\title{
Thermal behavior of hafnium-based ultrathin films on silicon
}

R. P. Pezzi, J. Morais, S. R. Dahmen, K. P. Bastos, L. Miotti, G. V. Soares, I. J. R. Baumvol, and F. L. Freire

Citation: Journal of Vacuum Science \& Technology A 21, 1424 (2003); doi: 10.1116/1.1575218

View online: https://doi.org/10.1116/1.1575218

View Table of Contents: https://avs.scitation.org/toc/jva/21/4

Published by the American Vacuum Society

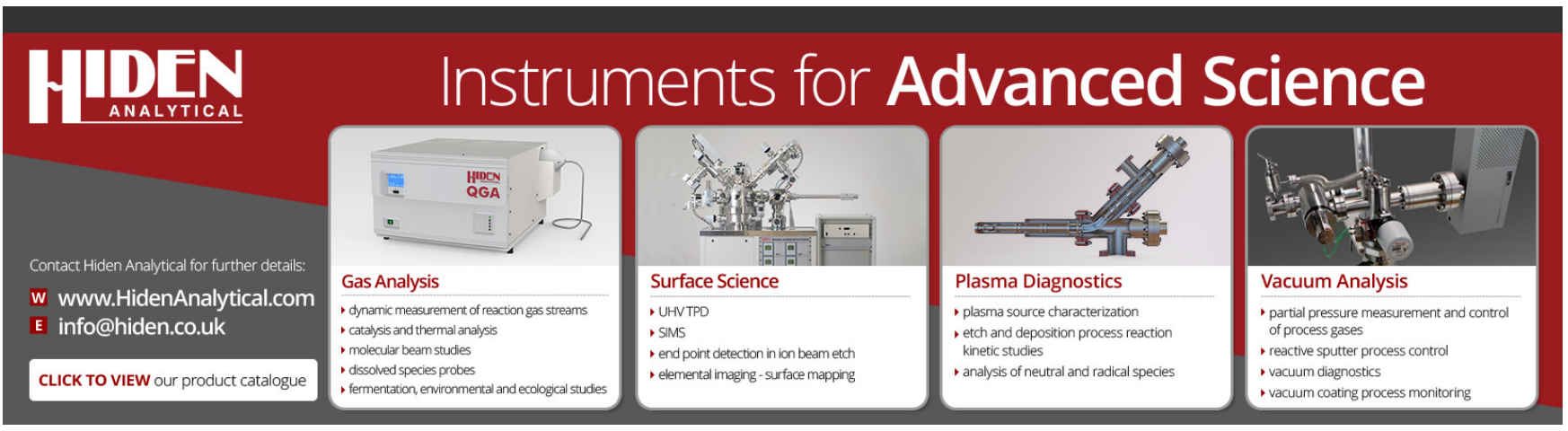




\title{
Thermal behavior of hafnium-based ultrathin films on silicon
}

\author{
R. P. Pezzi, J. Morais, S. R. Dahmen, K. P. Bastos, L. Miotti, G. V. Soares, \\ and I. J. R. Baumvola) \\ Instituto de Física, UFRGS, Av. Bento Gonçalves 9500, Porto Alegre, RS, Brazil 91509-900 \\ F. L. Freire, Jr. \\ Departamento de Física, PUC-RIO, Rua Marquês de São Vicente, 225, Rio de Janeiro, RJ, \\ Brazil 22452-970
}

(Received 25 November 2002; accepted 17 March 2003; published 2 July 2003)

\begin{abstract}
We report here on the thermodynamical stability of ultrathin, hafnium-based dielectric films, namely hafnium oxide $\left(\mathrm{HfO}_{2}\right)$, silicate $\left(\mathrm{HfSi}_{x} \mathrm{O}_{y}\right)$, and aluminum silicate $\left(\mathrm{AlHf}_{x} \mathrm{Si}_{y} \mathrm{O}_{z}\right)$, deposited on silicon. These materials are promising candidates to replace the well established silicon oxide and oxynitride as gate dielectric materials in advanced Si-based complementary metal-oxidesemiconductor technology. Since there are mandatory requirements on the gate dielectric material, hafnium oxide is currently being modified, by adding silicon and aluminum into the matrix, increasing its thermal stability, and improving its electrical properties. Diffusion-reaction during thermal processing was investigated using isotopic substitution together with ion beam techniques such as Rutherford backscattering spectrometry, narrow nuclear resonance profiling, and nuclear reaction analysis. The chemical changes in the films were accessed by $\mathrm{x}$-ray photoelectron spectroscopy. (C) 2003 American Vacuum Society. [DOI: 10.1116/1.1575218]
\end{abstract}

\section{INTRODUCTION}

The International Technology Roadmap for Semiconductors ${ }^{1}$ foresees that the silicon oxynitride interim solution for gate dielectric can be used for another two to four years. Then, further development in Si-based integrated circuits will rely on the use of alternative materials with dielectric constants much higher than that of silicon oxide or oxynitrides.

Although adequately low leakage currents have been reported for the capacitance equivalent to $\mathrm{SiO}_{2}$ thickness OET as low as $1 \mathrm{~nm}$ and less, ${ }^{2,3}$ there are many aspects that may prevent the introduction of high- $k$ dielectrics in advanced complementary metal-oxide-semiconductor (CMOS) fabrication technology. The first major difficulty comes from the fact that, besides having a dielectric constant substantially higher than that of $\mathrm{SiO}_{2}$ and $\mathrm{SiO}_{x} \mathrm{~N}_{y}$, any potential candidate for replacement as a gate dielectric must also have a (i) comparable energy band gap, (ii) comparably low $\left(\sim 10^{10} / \mathrm{cm}^{2}\right)$ defect charge density, and (iii) comparably low $\left(\sim 10^{10} / \mathrm{cm}^{2} \mathrm{eV}\right)$ density of electronic interface states. ${ }^{4}$ These conditions will be extremely hard to meet, especially condition (iii). For this reason, many recent studies point out that one or a few monolayers of $\mathrm{SiO}_{2}$ or $\mathrm{SiO}_{x} \mathrm{~N}_{y}$ will most probably be thermally grown as an intermediate layer, in order to preserve the outstanding electrical and structural quality of the $\mathrm{SiO}_{2} / \mathrm{Si}$ interface.

Furthermore, in order to maintain its integrity, any potential high- $k$ material must be as thermodynamically stable on $\mathrm{Si}$ as $\mathrm{SiO}_{2}$ or $\mathrm{SiO}_{x} \mathrm{~N}_{y}$, which means that in further processing steps following gate dielectric film deposition. (i) The chemical reaction in the bulk and at the high- $k$ dielectric/Si interface ${ }^{5}$ must be prevented, (ii) the oxygen diffusion

a)Electronic address: israel@if.ufrgs.br through the high $k$ film and oxygen reaction with a Si substrate must be controlled, and (iii) migration and eventual segregation of any element, especially at the electrode/ dielectric and dielectric/Si interfaces, must be avoided. The results point out to very few metal oxides combining stability on $\mathrm{Si}$ and dielectric constant appreciably higher than $\mathrm{SiO}_{x} \mathrm{~N}_{y}$. Among them, one can mention $\mathrm{ZrO}_{2}, \mathrm{HfO}_{2}$, $\mathrm{Al}_{2} \mathrm{O}_{3}$, and $\mathrm{Y}_{2} \mathrm{O}_{3}$. One final, very delicate concern is the recrystallization ${ }^{4}$ of the initially amorphous high- $k$ dielectric films, which would lead to a dramatic increase of leakage current due to grain-boundary conduction. Unlike $\mathrm{SiO}_{2}$, many metal-oxide films have a strong driving force to crystallize. The addition of either $\mathrm{Si}$ or Al to metal-oxide films on Si can eliminate or strongly reduce the crystallization of these films and this practice is assuming an important role in the search for an alternative gate dielectric material.

The aim of this article is to report on atomic transport and chemical reaction processes during high-temperature annealing of hafnium-based high- $k$ dielectrics on $\mathrm{Si}$. As the thicknesses of the dielectric films range from 1 to $10 \mathrm{~nm}$, the probing techniques used to investigate the thermal stability of the films must have high depth resolution and sensitivity. This makes ion beam techniques such as Rutherford backscattering spectrometry (RBS), nuclear reaction analysis (NRA), and narrow nuclear resonance profiling (NNRP) ${ }^{6}$ suitable to infer compositions and atomic distributions of the elements in the ultrathin films, and their behavior upon annealing. To investigate oxygen diffusion in the films, annealing in a low-pressure oxygen atmosphere enriched to $97 \%$ in the ${ }^{18} \mathrm{O}$ isotope was performed. This allows us to distinguish between oxygen previously existent in the film from the newly incorporated during annealing, ${ }^{6}$ and also to determine its depth profile by NNRP, using the narrow resonance at 151 $\mathrm{keV}$ in the cross section curve of the ${ }^{18} \mathrm{O}(p, \alpha){ }^{15} \mathrm{~N}$ nuclear 
reaction. Channeled RBS was used to estimate the oxygen content in the films. To enhance the depth resolution, RBS was also carried out with a highly tilded geometry, with grazing angle detection to estimate the $\mathrm{Hf}$ distribution. ${ }^{6}$ The chemical environment of the elements in the films were analyzed by x-ray photoelectron spectroscopy (XPS), excited by $\mathrm{Mg} K \alpha$ radiation of $1253.6 \mathrm{eV}$ with a take-off angle of $\theta$ $=45$, where not explicitly specified.

\section{HAFNIUM DIOXIDE}

Atomic composition and transport and chemical reaction studies during annealing in oxygen of polycrystalline ultrathin $\mathrm{HfO}_{2}$ films (ellipsometric thickness of $5 \mathrm{~nm}$ ) deposited in $\mathrm{Si}(001)$ substrates were studied. The $\mathrm{Si}$ wafers were thermally oxynitrided in NO prior to metal-oxide deposition. The starting structure was prepared by the following sequence: HF cleaning of silicon wafers, followed by annealing in $\mathrm{NO}$, and followed by metalorganic chemical vapor deposition (MOCVD) of $\mathrm{HfO}_{2}$ at $550{ }^{\circ} \mathrm{C}$ using $\mathrm{Hf}-t$-butoxide and an oxidant gas. The wafers were then subjected to postdeposition rapid thermal annealing (RTA) in $\mathrm{Ar}_{2} \mathrm{~N}_{2}$ at $1000{ }^{\circ} \mathrm{C}$ for $10 \mathrm{~s}$ (Ar annealing), in order to simulate a typical dopant-annealing step. Finally, the wafers were subjected to RTA in $\mathrm{O}_{2}$ at $800^{\circ} \mathrm{C}$ for 10 or $60 \mathrm{~s}\left(\mathrm{O}_{2}\right.$ annealing), simulating any of the several usual thermal processing steps. This last annealing step was also alternatively performed in 7 $\times 10^{3} \mathrm{~Pa}$ of $\mathrm{O}_{2}, 97 \%$ enriched in the ${ }^{18} \mathrm{O}$ isotope $\left({ }^{18} \mathrm{O}_{2}\right.$ annealing). Furthermore, these ${ }^{18} \mathrm{O}_{2}$ annealings were performed with and without $\mathrm{Ar}$ preannealing, aimed at investigating the effects of the two thermal steps separately.

RBS was carried out using $1 \mathrm{MeV} \mathrm{He}^{+}$ions in a channeled geometry and detection at $100^{\circ}$ with the incidence direction, as shown in the inset of Fig. 1(b). The signals corresponding to particles backscattered by silicon, oxygen, and nitrogen atoms present in samples 1 (open down triangles), 2 (open circles), and 3 (solid triangles), are plotted in Fig. 1(a), together with the hafnium signal in the inset. From the inset of Fig. 1(a), we can conclude that the amount and depth distribution of Hf remain unchanged after annealing, within the depth resolution of the technique. Table I shows the areal densities of $\mathrm{Hf}$ and $\mathrm{Si}$ (as determined by channeled RBS) and of ${ }^{16} \mathrm{O},{ }^{18} \mathrm{O}$, and ${ }^{14} \mathrm{~N}$ (as determined by NRA). $\mathrm{O}_{2}$ annealing for $60 \mathrm{~s}$ (sample 3 in Table I) produces an increase on the O-areal density of about $30 \%$ with respect to the as-prepared sample (sample 1) and a comparable percentage decrease on the $\mathrm{N}$-areal density. Figure $1(\mathrm{~b})$ shows $\mathrm{Si},{ }^{16} \mathrm{O}$, and ${ }^{18} \mathrm{O}$ signals in channeled-RBS spectra of ${ }^{18} \mathrm{O}_{2}$-annealed samples for $10 \mathrm{~s}$, with and without Ar preannealing (samples 5 and 6 in Table I). One notices the presence of ${ }^{16} \mathrm{O}-{ }^{18} \mathrm{O}$ exchange, which increases with time of annealing in ${ }^{18} \mathrm{O}_{2}$ and is much larger for samples that were annealed in ${ }^{18} \mathrm{O}_{2}$ only than for those that were preannealed in $\mathrm{Ar}$.

Excitation curves of the ${ }^{18} \mathrm{O}(p, \alpha){ }^{15} \mathrm{~N}$ nuclear reaction around the resonance at $151 \mathrm{keV}\left(\Gamma_{r}=100 \mathrm{eV}\right)$ and ${ }^{18} \mathrm{O}$ profiles (depth resolution of approximately $0.7 \mathrm{~nm}$ near the surface) of as-prepared and ${ }^{18} \mathrm{O}_{2}$-annealed samples are shown in Fig. 2. The ${ }^{18} \mathrm{O}$ profiles in samples 5 and 7 (preannealing in

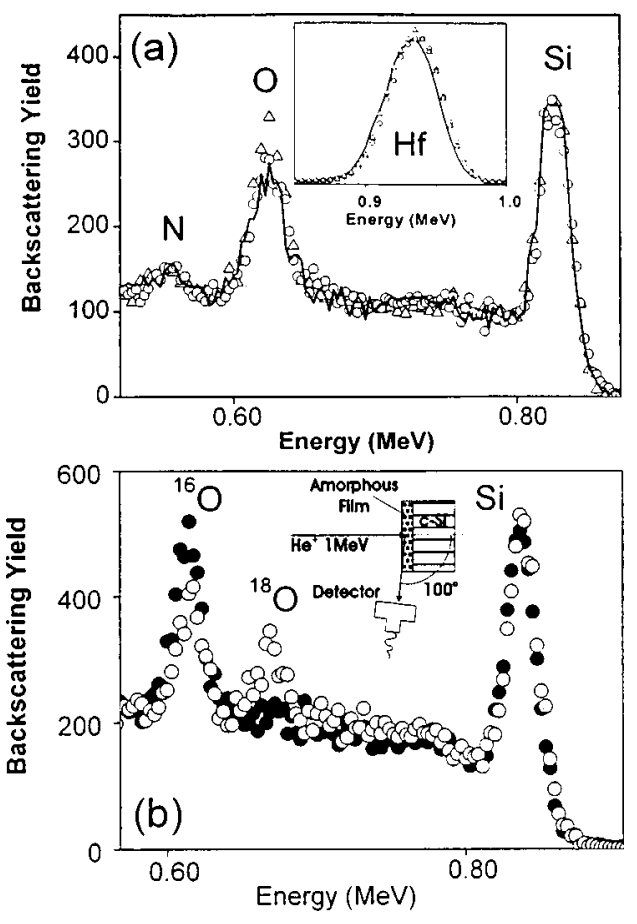

FIG. 1. Channeled-RBS spectra of $1 \mathrm{MeV}$ incident $\mathrm{He}^{+}$from $\mathrm{HfO}_{2}$ films on $\mathrm{Si}$, with detection of the scattered ions at $100^{\circ}$ with the direction of incidence. (a) As-prepared sample (solid line), Ar annealing at $1000{ }^{\circ} \mathrm{C}$ for $10 \mathrm{~s}$ followed by $\mathrm{O}_{2}$ annealing at $800{ }^{\circ} \mathrm{C}$ for $10 \mathrm{~s}$ (open circles) and $60 \mathrm{~s}$ (triangles). The corresponding $\mathrm{Hf}$ signals are shown in the inset (tilted geometry): (b) Ar annealing at $1000{ }^{\circ} \mathrm{C}$ for $10 \mathrm{~s}$ followed by ${ }^{18} \mathrm{O}_{2}$ annealing at $800{ }^{\circ} \mathrm{C}$ for $10 \mathrm{~s}$ (solid circles) and ${ }^{18} \mathrm{O}_{2}$ annealing only at $800{ }^{\circ} \mathrm{C}$ for $10 \mathrm{~s}$ (open circles).

Ar+ 10 or $60 \mathrm{~s}$ of ${ }^{18} \mathrm{O}_{2}$ annealing) indicate a propagating ${ }^{18} \mathrm{O}$ front from the surface and reaction (eventually ${ }^{16} \mathrm{O}-{ }^{18} \mathrm{O}$ and $\mathrm{N}-{ }^{18} \mathrm{O}$ exchange reactions only) with the $\mathrm{HfO}_{2}$ network. Furthermore, ${ }^{18} \mathrm{O}$ profiles in samples 6 and $8\left({ }^{18} \mathrm{O}_{2}\right.$ annealing only for 10 and $60 \mathrm{~s}$ ) are deeper and higher. When compared to similar studies performed previously ${ }^{7-11}$ in aluminum, zirconium, and gadolinium oxides and silicates, the present $\mathrm{HfO}_{2} / \mathrm{SiO}_{x} \mathrm{~N}_{y}$ structure displays higher resistance to oxygen migration from the gas into the solid phase and incorporation therein, as well as smaller isotopic exchanges. ${ }^{29} \mathrm{Si}$ profiles were determined by NNRP (results not shown here), revealing that $\mathrm{Si}$ remains immobile during annealing, in contrast to

TABLE I. Areal densities (in units of $10^{15} \times \mathrm{cm}^{-2}$ ) of different atomic species and isotopes in $\mathrm{HfO}_{2}$ films on $\mathrm{Si}$. Ar annealing at $1000{ }^{\circ} \mathrm{C}$. Annealings in ${ }^{16} \mathrm{O}_{2}$ and ${ }^{18} \mathrm{O}_{2}$ at $800{ }^{\circ} \mathrm{C}$.

\begin{tabular}{lccccc}
\hline \hline \multicolumn{1}{c}{ Sample } & Hf & $\mathrm{Si}$ & ${ }^{16} \mathrm{O}$ & ${ }^{18} \mathrm{O}$ & ${ }^{14} \mathrm{~N}$ \\
\hline (1) As prepared & 9.5 & 1.4 & 22.2 & 0.02 & 1.6 \\
(2) $\mathrm{Ar}+\mathrm{O}_{2} 10 \mathrm{~s}$ & 9.6 & 1.4 & 24.3 & 0.02 & 1.5 \\
(3) $\mathrm{Ar}+\mathrm{O}_{2} 60 \mathrm{~s}$ & 9.8 & 1.8 & 28.5 & 0.02 & 1.2 \\
(4) $\mathrm{Ar}$ anneal & 9.6 & 1.5 & 23.2 & 0.02 & 1.6 \\
(5) $\mathrm{Ar}+{ }^{18} \mathrm{O}_{2} 10 \mathrm{~s}$ & 9.6 & 1.5 & 22.4 & 0.51 & 1.5 \\
(6) ${ }^{18} \mathrm{O}_{2} 10 \mathrm{~s}$ & 9.8 & 1.7 & 19.1 & 6.54 & 1.4 \\
(7) $\mathrm{Ar}+{ }^{18} \mathrm{O}_{2} 60 \mathrm{~s}$ & 9.5 & 1.7 & 22.3 & 4.76 & 1.2 \\
(8) ${ }^{18} \mathrm{O}_{2} 60 \mathrm{~s}$ & 9.6 & 2.2 & 15.4 & 11.13 & 1.1 \\
\hline \hline
\end{tabular}




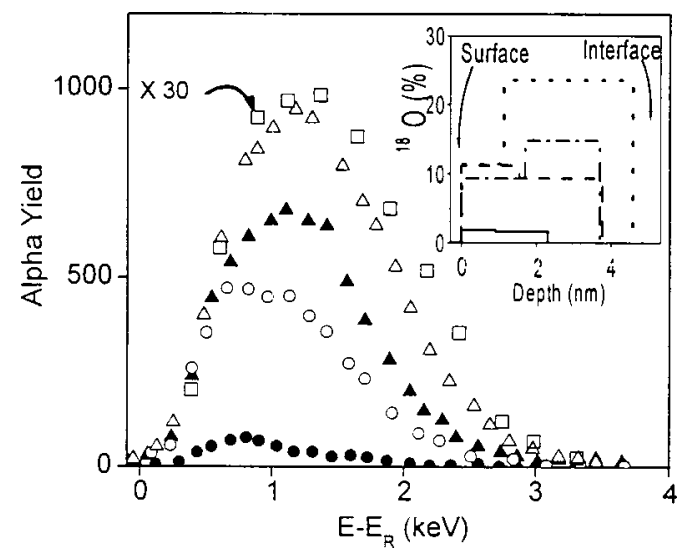

Fig. 2. Excitation curves of the ${ }^{18} \mathrm{O}_{2}(p, \alpha){ }^{15} \mathrm{~N}$ nuclear reaction around the resonance at $151 \mathrm{keV}$ for $\mathrm{HfO}_{2}$ films on $\mathrm{Si}$, with the corresponding ${ }^{18} \mathrm{O}$ profiles in the inset: As-prepared sample (sample 1) (open squares, $\times 30$ ), $\mathrm{Ar}$ annealing at $1000{ }^{\circ} \mathrm{C}$ for $10 \mathrm{~s}$ followed by ${ }^{18} \mathrm{O}_{2}$ annealing at $800{ }^{\circ} \mathrm{C}$ for $10 \mathrm{~s}$ (sample 5) (solid circles, solid curve), $60 \mathrm{~s}$ (sample 7) (solid triangles, dashed-dotted curve), ${ }^{18} \mathrm{O}_{2}$ annealing only at $800{ }^{\circ} \mathrm{C}$ for $10 \mathrm{~s}$ (sample 6) (open circles, dashed curve), and $60 \mathrm{~s}$ (sample 8) (open triangles, dotted curve).

several of the earlier mentioned materials where substrate $\mathrm{Si}$ is seen to migrate into the oxide film. ${ }^{7,9-11}$

Figure 3 shows $\operatorname{Si} 2 p$ photoelectron regions for asprepared and $\mathrm{O}_{2}$-annealed (10 and $60 \mathrm{~s}$ ) samples. The $\mathrm{Hf} 4 f$ and $\mathrm{O} 1 s$ regions for the as-prepared sample are shown in the insets, of Fig. 3, being almost identical to those for the annealed samples. The $\mathrm{Si} 2 p$ region for the starting sample has three components; one around the binding energy of $99.5 \mathrm{eV}$ commonly associated with $\mathrm{Si}-\mathrm{Si}$ bonds ( $\mathrm{Si}-\mathrm{Si}$ component), another around $103.2 \mathrm{eV}$ associated with different $\mathrm{Si}-\mathrm{O}$ bonding configurations, including $\mathrm{Si}-\mathrm{O}-\mathrm{Hf}$ bonds (Si-O component), ${ }^{2,12}$ and a third, much smaller component around $101 \mathrm{eV}$ associated with $\mathrm{Si}$ in an oxynitride bonding configuration ( $\mathrm{Si}-\mathrm{O}-\mathrm{N}$ component). ${ }^{12}$ According to literature, ${ }^{2,3,12}$ the $\mathrm{Hf} 4 f$ signal here observed is mostly due to $\mathrm{HfO}_{2}$, although minor contributions from $\mathrm{Hf}-\mathrm{O}-\mathrm{Si}$ and Hf $-\mathrm{O}-\mathrm{N}$ bonds cannot be excluded. Similarly, the O $1 \mathrm{~s}$ signal is attributed ${ }^{2}$ mainly to $\mathrm{O}-\mathrm{Hf}$ bonds, with a small contribution of $\mathrm{O}$ bonded to $\mathrm{Si}$ near the interface. The film

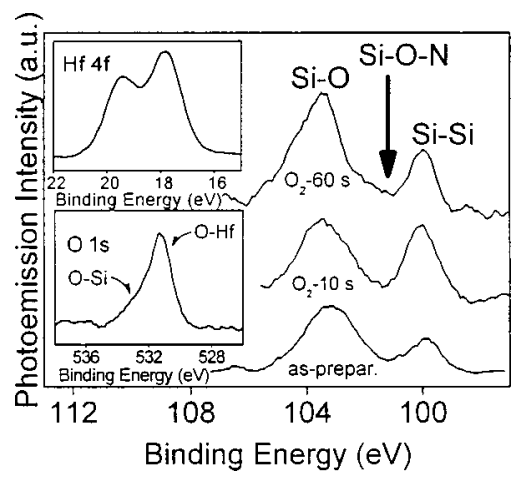

Fig. 3. Si $2 p$ photoelectron regions for $\mathrm{HfO}_{2}$ films on $\mathrm{Si}$ : As-prepared sample and for the samples $\mathrm{Ar}$ annealed at $1000{ }^{\circ} \mathrm{C}$ for $10 \mathrm{~s}$ followed by $\mathrm{O}_{2}$ annealing at $800{ }^{\circ} \mathrm{C}$ for 10 and $60 \mathrm{~s}$. The $\mathrm{Hf} 4 f$ and $\mathrm{O} 1 s$ regions for the as-prepared sample are shown in the insets. composition is then essentially $\mathrm{HfO}_{2}$, whereas the interface region has a complex composition, including $\mathrm{SiO}_{2}, \mathrm{SiO}_{x} \mathrm{~N}_{y}$, $\mathrm{SiHf}_{x} \mathrm{O}_{y}$ (Ref. 13) and $\mathrm{SiHf}_{x} \mathrm{O}_{y} \mathrm{~N}_{z}$. The $\mathrm{Si}-\mathrm{Si} / \mathrm{Si}-\mathrm{O}$ area ratio increases significantly from the as-prepared to the $10 \mathrm{~s}$ $\mathrm{O}_{2}$-annealed sample, which could be indicative either of chemical reactions taking place at the interface, or of a higher $\mathrm{Si}-\mathrm{Si}$ contribution due to the loss of atoms from the $\mathrm{HfO}_{2} / \mathrm{SiO}_{x} \mathrm{~N}_{y}$ film. However, this ratio remains constant from the as-deposited to the $60 \mathrm{~s} \mathrm{O}_{2}$-annealed sample, excluding these possibilities. RBS and NRA data of Table I also exclude $\mathrm{HfO}_{2} / \mathrm{SiO}_{x} \mathrm{~N}_{y}$ losses as a possibility. Owing to substantial thinning of the $\mathrm{HfO}_{2}$ films ${ }^{13,14}$ following $\mathrm{Ar}$ annealing, an increase of the $\mathrm{Si}-\mathrm{Si}$ component contribution from the substrate is expected. The subsequent $\mathrm{O}_{2}$ annealing for $10 \mathrm{~s}$ does not lead a significant amount of oxygen from the gas phase to oxidize $\mathrm{Si}$ at the interface (see Figs. 1 and 2 and Table I). Consequently, an increase in the $\mathrm{Si}-\mathrm{Si} / \mathrm{Si}-\mathrm{O}$ ratio is observed, as seen in the hafnium silicate, bellow, and other authors concerning dielectrics containing hafnium. On the other hand, a subsequent $60 \mathrm{~s}_{2}$ annealing substantially increases the oxygen content, as well as leads oxygen from the gas phase to reach the interface, oxidizing a Si substrate and thus compensating the increase of the $\mathrm{Si}-\mathrm{Si}$ component from the substrate due to thinning by a comparable increase of the $\mathrm{Si}-\mathrm{O}$ component.

The present characterizations indicate an intermediate layer of complex composition between the MOCVD $\mathrm{HfO}_{2}$ films and the $\mathrm{Si}$ substrate, including silicon oxynitride, hafnium silicate, and possibly hafnium-silicon oxynitride. The composition of this structure is essentially stable against Ar preannealing at $1000{ }^{\circ} \mathrm{C}$ and $\mathrm{O}_{2}$ annealing at $800^{\circ} \mathrm{C}$. Oxygen migration proceeds by means of a propagating front from the surface that reacts with the $\mathrm{HfO}_{2} / \mathrm{SiO}_{x} \mathrm{~N}_{y}$ network as it advances, the main reaction channels being $\mathrm{O}-\mathrm{O}$ and $\mathrm{O}-\mathrm{N}$ exchanges. For the annealing temperatures and times of the present work, the $\mathrm{HfO}_{2} / \mathrm{SiO}_{x} \mathrm{~N}_{y}$ structure showed more resistance to $\mathrm{O}$ and $\mathrm{Si}$ migration and incorporation than others studied previously, with the Ar preannealed samples exhibiting a higher resistance than those directly annealed in $\mathrm{O}_{2}$. The intermediate layer is also essentially stable against annealing, apart from moderate $\mathrm{N}$ loss due to $\mathrm{N}-\mathrm{O}$ exchange reaction and $\mathrm{SiO}_{2}$ formation due to oxidation of the substrate. We attribute this stability to a synergism between the properties of $\mathrm{HfO}_{2}$ films on $\mathrm{Si}$ and the reaction-diffusion barrier constituted by both the $\mathrm{SiO}_{x} \mathrm{~N}_{y}$ interlayer and $\mathrm{N}$ eventually incorporated into the $\mathrm{HfO}_{2}$ films.

\section{HAFNIUM SILICATE}

The hafnium silicate films, which are actually $\left(\mathrm{HfO}_{2}\right)_{1-x}\left(\mathrm{SiO}_{2}\right)_{x}$ pseudobinary alloys or compounds, ${ }^{15,16}$ were deposited by reactive sputtering in $\mathrm{O}_{2}$ on HF-cleaned, $200 \mathrm{~mm} \mathrm{Si}(100) p$-type substrates. RTA was performed at $1000{ }^{\circ} \mathrm{C}$ in $\mathrm{N}_{2}\left(\mathrm{~N}_{2}\right.$ annealing $)$ and $\mathrm{O}_{2}\left(\mathrm{O}_{2}\right.$ annealing $)$ at atmospheric pressure. RTA in $\mathrm{O}_{2}$ was also performed at $1000^{\circ} \mathrm{C}$ in $7 \times 10^{3} \mathrm{~Pa}$ of $\mathrm{O}_{2} 97 \%$ enriched in the ${ }^{18} \mathrm{O}$ isotope 
$\left({ }^{18} \mathrm{O}_{2}\right.$ annealing). This allows differentiation between oxygen incorporated from the gas phase and that previously existing in the films.

Cross section high-resolution transmission electron microscopy (HRTEM) images (not shown) revealed that the as-deposited sample consisted of an amorphous $\left(\mathrm{HfO}_{2}\right)_{1-x}\left(\mathrm{SiO}_{2}\right)_{x}$ layer approximately $3 \mathrm{~nm}$ thick and an underlying amorphous $\mathrm{SiO}_{2}$-like layer formed on the $\mathrm{Si}$ substrate during deposition. HRTEM also indicated that $\mathrm{N}_{2}$ annealing leads to a densification (thinning) of the $\left(\mathrm{HfO}_{2}\right)_{1-x}\left(\mathrm{SiO}_{2}\right)_{x}$ layer, and to an increase of the thickness of the $\mathrm{SiO}_{2}$ layer. The same effects are observed following $\mathrm{O}_{2}$ annealing, in which case a larger increase of the $\mathrm{SiO}_{2}$ layer is observed. In all cases, annealing produces an increase in the crystallization of the films.

The $3 \mathrm{~nm}$ thick $\left(\mathrm{HfO}_{2}\right)_{1-x}\left(\mathrm{SiO}_{2}\right)_{x}$ films were also analyzed by angle-resolved XPS. The top of Fig. 4 shows $\mathrm{Si} 2 p$ signals for the as-deposited sample and for $\mathrm{N}_{2}$ - and $\mathrm{O}_{2}$-annealed samples, measured at two different take-off angles between the sample normal and the analyzer axis, namely $60^{\circ}$ (surface sensitive mode) and $25^{\circ}$ (bulk sensitive mode). The surface sensitive signals were fitted with two components, one associated with $\mathrm{Si}-\mathrm{O}$ bonds and another correspondent with $\mathrm{Si}-\mathrm{O}-\mathrm{Hf}$ bonds. The ratios between these two components remain approximately constant after annealing. The bulk sensitive signals were fitted with the two aforementioned components plus a third one associated with $\mathrm{Si}-\mathrm{Si}$ bonds from the substrate. One notices a decrease in the intensity of the $\mathrm{Si}-\mathrm{Si}$ component with respect to the $\mathrm{Si}-\mathrm{O}$ and $\mathrm{Si}-\mathrm{O}-\mathrm{Hf}$ components in the sample annealed in $\mathrm{O}_{2}$, owing to the increase in thickness of the interlayer as corroborated by HRTEM. This increase in thickness may be due either to the formation of $\mathrm{SiO}_{2}$ or, eventually, of additional hafnium silicate. The bottom of Fig. 4 shows the $\mathrm{O} 1 \mathrm{~s}$ signals, which can be fitted with two components, one associated with $\mathrm{O}-\mathrm{Si}$ bonds and another associated with $\mathrm{O}-\mathrm{Hf}$ bonds. The strong increase in the intensity of the $\mathrm{O}-\mathrm{Hf}$ component with respect to the $\mathrm{O}-\mathrm{Si}$ component in the bulksensitive signal of the $\mathrm{O}_{2}$-annealed sample shows that the compound responsible for the increase of the interlayer thickness was a silicate rather than $\mathrm{SiO}_{2}$.

Elemental composition of the as-deposited samples was determined by RBS and NRA to be approximately $\mathrm{HfSi}_{2} \mathrm{O}_{5}$, which remained essentially the same after $60 \mathrm{~s}$ RTA at $1000{ }^{\circ} \mathrm{C}$ in $\mathrm{N}_{2}$ and $\mathrm{O}_{2}$. Channeled-RBS spectra of $1 \mathrm{MeV}$ incident $\mathrm{He}^{+}$ions from the as-deposited and $\mathrm{N}_{2^{-}}$and $\mathrm{O}_{2}$-annealed samples are shown in Fig. 5, evidencing that annealing in $\mathrm{N}_{2}$ leads to a slight increase in the areal density of oxygen of the samples, while annealing in $\mathrm{O}_{2}$ leads to a substantial increase in the oxygen areal density. The Hf signal is shown in the inset of Fig. 5(a), using the tilted geometry, where one notices the immobility of $\mathrm{Hf}$ within the depth resolution.

${ }^{18} \mathrm{O}_{2}$ annealing of the samples shown in Fig. 5(a) leads to the channeled-RBS spectra shown in Fig. 5(b). One notices the incorporation of ${ }^{18} \mathrm{O}$ from the gas phase into the $\left(\mathrm{HfO}_{2}\right)_{1-x}\left(\mathrm{SiO}_{2}\right)_{x} / \mathrm{SiO}_{2}$ film structure.
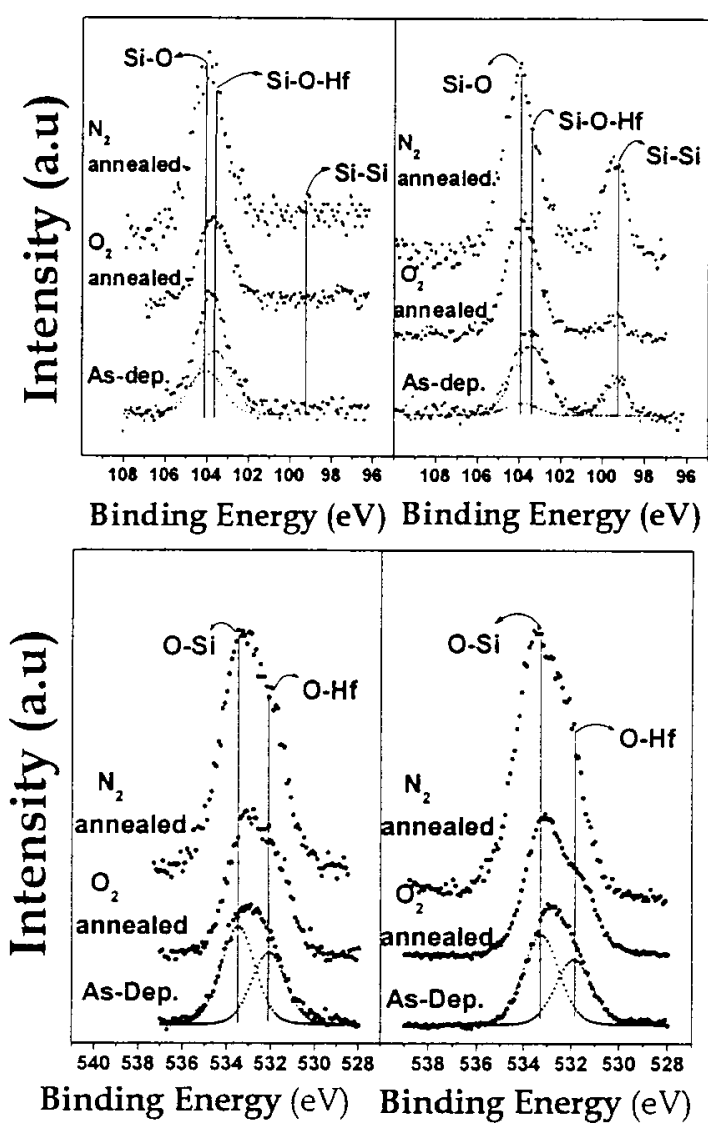

FIG. 4. (Top) - Si $2 p$ photoelectron spectra in surface sensitive (left-hand side, take-off angle $\theta=60^{\circ}$ ) and bulk sensitive (right-hand side, take-off angle $\theta=25^{\circ}$ ) from as-deposited, vacuum, and $\mathrm{O}_{2}$-annealed hafniumsilicate films on Si. (Bottom)-The corresponding O $1 s$ photoelectrons.

${ }^{18} \mathrm{O}$ profiles in these hafnium silicate film samples were determined by NNRP as just discussed. The oxygen front from the gas phase diffuses from the surface reacting with the hafnium-silicate network. Samples that were preannealed in either $\mathrm{O}_{2}$ or $\mathrm{N}_{2}$ are more resistant to the propagation of the ${ }^{18} \mathrm{O}$ front than the as-deposited one. Therefore, less ${ }^{18} \mathrm{O}$ will reach and oxidize the $\mathrm{Si}$ substrate in the preannealed samples than in the as-deposited one. ${ }^{29} \mathrm{Si}$ profiles were determined for the $\mathrm{O}_{2}$-annealed samples using the ${ }^{29} \mathrm{Si}(p, \gamma){ }^{30} \mathrm{P}$ nuclear reaction around the resonance at 414 $\mathrm{keV}(\Gamma=100 \mathrm{eV})$. Excitation curves and extracted profiles are shown in Fig. 6. In the bulk of the as-deposited samples, a roughly constant $\mathrm{Si}$ concentration is observed, which remained essentially immobile during $1000{ }^{\circ} \mathrm{C}$ annealing. There is no observable transport of $\mathrm{Si}$ from the substrate into the $\mathrm{HfSi}_{x} \mathrm{O}_{y}$ films after annealing, revealing high stability of the bulk and interface regions in contrast with several previously studied materials such as $\mathrm{Al}_{2} \mathrm{O}_{3}, \mathrm{ZrO}_{2}, \mathrm{Zr}-\mathrm{Si}-\mathrm{O}$, and $\mathrm{Zr}-\mathrm{Al}-\mathrm{O}^{7-13}$

In the particular case of $\mathrm{HfSi}_{x} \mathrm{O}_{y}$ films on $\mathrm{Si}$ studied here, good stability and integrity were observed when they are submitted to RTA at $1000{ }^{\circ} \mathrm{C}$, especially if we consider that $30 \mathrm{~s}$ of RTA processing is more than enough for most dopant-annealing processing steps. Preannealing in a nonreactive atmosphere like $\mathrm{N}_{2}$ increases the stability and 

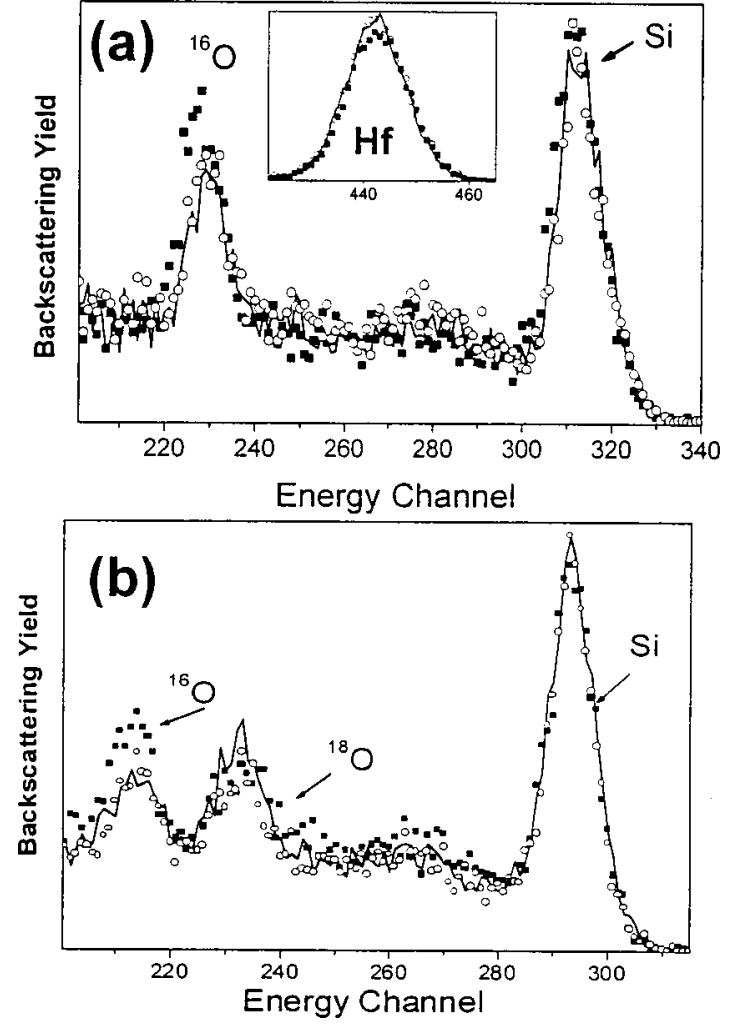

FIG. 5. Channeled-RBS spectra of $1 \mathrm{MeV}$ incident $\mathrm{He}^{+}$ions from hafniumsilicate films on $\mathrm{Si}$ (a) as-deposited (solid line) and after annealing in $\mathrm{N}_{2}$ (open circles) and $\mathrm{O}_{2}$ (solid circles) at $1000{ }^{\circ} \mathrm{C}$ for $60 \mathrm{~s}$ and (b) the same samples as in (a), after a second processing step, RTA in ${ }^{18} \mathrm{O}_{2}$ at $1000{ }^{\circ} \mathrm{C}$ for $60 \mathrm{~s}$.

resistance to oxidation of the films. Annealing in an oxygencontaining atmosphere reveals a rapidly propagating front of oxygen from the film surface, which reacts with the $\left(\mathrm{HfO}_{2}\right)_{1-x}\left(\mathrm{SiO}_{2}\right)_{x}$ network as it advances. When compared to previous materials considered for $\mathrm{SiO}_{2}$ replacements as gate dielectric, such as $\mathrm{Al}_{2} \mathrm{O}_{3}, \mathrm{ZrO}_{2}, \mathrm{Zr}-\mathrm{Si}-\mathrm{O}, \mathrm{Zr}-\mathrm{Al}-\mathrm{O}$,

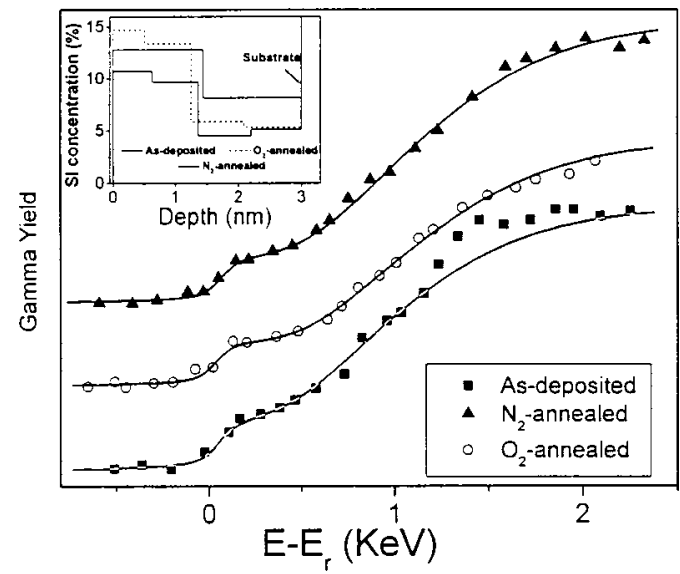

FIG. 6. Excitation curves of the ${ }^{29} \mathrm{Si}(p, \gamma){ }^{30} \mathrm{P}$ nuclear reaction around the resonance at $414 \mathrm{keV}$ with the corresponding ${ }^{29} \mathrm{Si}$ profiles in the inset from $\left(\mathrm{HfO}_{2}\right)_{1-x}\left(\mathrm{SiO}_{2}\right)_{x}$ on $\mathrm{Si}$, as-deposited (squares), $\mathrm{N}_{2}$-annealed (triangles), and $\mathrm{O}_{2}$-annealed (circles) samples. The curves are shifted to improve clarity.
TABLE II. Annealing parameters for $\mathrm{AlHf}_{x} \mathrm{Si}_{y} \mathrm{O}_{z}$ films, performed in 7 $\times 10^{3} \mathrm{~Pa}$ of $\mathrm{O}_{2}$ enriched to $97 \%$ in the ${ }^{18} \mathrm{O}$ isotope $\left({ }^{18} \mathrm{O}_{2}\right)$, with the corresponding areal densities of $\mathrm{Hf},{ }^{18} \mathrm{O}$, and ${ }^{16} \mathrm{O}$ present in the films, in units of $10^{15} \times \mathrm{cm}^{-2}$.

\begin{tabular}{cccccc}
\hline \hline Sample & Temperature & Time & Hf & ${ }^{18} \mathrm{O}$ & ${ }^{16} \mathrm{O}$ \\
\hline 1 & as deposited & $\cdots$ & 4.79 & $\cdots$ & 24.75 \\
2 & $600{ }^{\circ} \mathrm{C}$ & $30 \mathrm{~s}$ & 4.72 & 0.65 & 24.92 \\
3 & $600^{\circ} \mathrm{C}$ & $90 \mathrm{~s}$ & 4.61 & 1.31 & 25.84 \\
4 & $600^{\circ} \mathrm{C}$ & $180 \mathrm{~s}$ & 5.06 & 1.71 & 26.00 \\
5 & $800^{\circ} \mathrm{C}$ & $60 \mathrm{~s}$ & 4.88 & 1.78 & 24.33 \\
6 & $800^{\circ} \mathrm{C}$ & $90 \mathrm{~s}$ & 4.29 & 1.90 & 23.56 \\
7 & $800^{\circ} \mathrm{C}$ & $180 \mathrm{~s}$ & 5.03 & 5.94 & 21.60 \\
8 & $1000^{\circ} \mathrm{C}$ & spike & 4.94 & 17.64 & 21.61 \\
9 & $1000^{\circ} \mathrm{C}$ & $10 \mathrm{~s}$ & 4.55 & 12.10 & 21.48 \\
10 & $1000^{\circ} \mathrm{C}$ & $20 \mathrm{~s}$ & 3.87 & 10.94 & 21.13 \\
\hline \hline
\end{tabular}

$\mathrm{Gd}_{2} \mathrm{O}_{3}, \mathrm{Gd}-\mathrm{Si}-\mathrm{O}$, and others, the hafnium silicate films present higher stability under annealing at $1000^{\circ} \mathrm{C}$.

\section{HAFNIUM ALUMINUM SILICATE}

The $\mathrm{AlHf}_{x} \mathrm{Si}_{y} \mathrm{O}_{z}$ films were deposited by reactive sputtering, using a $\mathrm{HfO}_{2}$ target partially covered with pieces of aluminum and silicon. In order to observe the behavior of the material when different processing parameters are varied, the as-deposited, $3.5 \mathrm{~nm}$ thick $\mathrm{AlHf}_{x} \mathrm{Si}_{y} \mathrm{O}_{z}$ films were submitted to nine different annealing conditions in ${ }^{18} \mathrm{O}_{2}$, maintaining the same ${ }^{18} \mathrm{O}_{2}$ pressure, as shown in Table II, which includes a spike annealing at $1000^{\circ} \mathrm{C}$.

Figure 7 shows channeled-RBS spectra of the asdeposited and annealed $\left(10 \mathrm{~s}\right.$ at $\left.1000^{\circ} \mathrm{C}\right)$ samples, where one can clearly notice the incorporation of ${ }^{18} \mathrm{O}$ in the film, without a noticeable loss of ${ }^{16} \mathrm{O}$, see Table II. The corresponding Hf signals are shown in the inset of Fig. 7. The geometry used was the same as used in previous sections. RBS revealed that hafnium amounts and the corresponding depth distribution were essentially constant for all annealing conditions and that ${ }^{18} \mathrm{O}$ is incorporated in significantly smaller amounts than in hafnium oxide or silicate films on $\mathrm{Si}$.

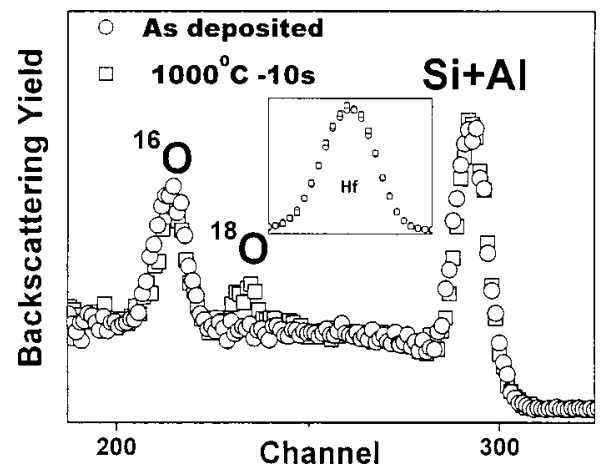

FIG. 7. Channeled-RBS spectra of $1 \mathrm{MeV}$ incident $\mathrm{He}^{+}$, with detection of the scattered ions at $100^{\circ}$ with the direction of incidence, from hafniumaluminum-silicate films on Si: As-prepared sample (open circles), and after ${ }^{18} \mathrm{O}_{2}$ annealing at $1000{ }^{\circ} \mathrm{C}$ for $10 \mathrm{~s}$ (open squares). The corresponding $\mathrm{Hf}$ signals are shown in the inset. 


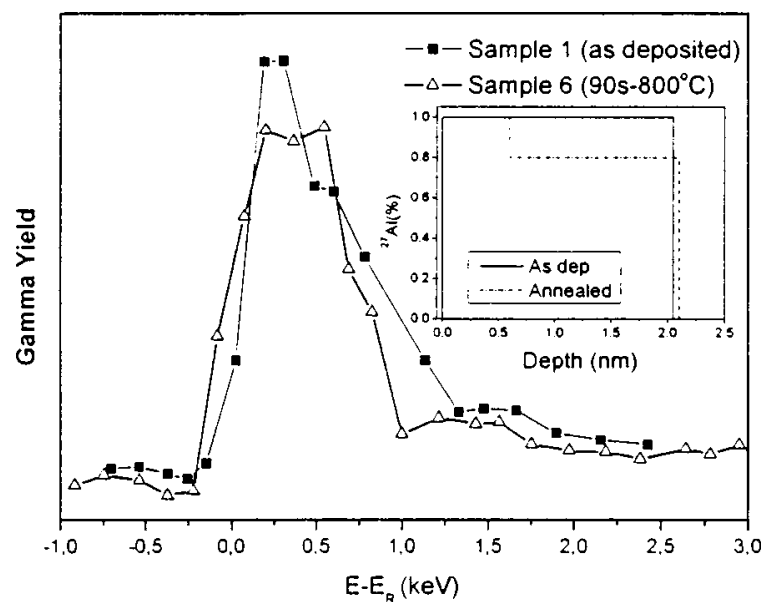

FIG. 8. Excitation curves of the ${ }^{27} \mathrm{Al}(p, \gamma){ }^{28} \mathrm{Si}$ nuclear reaction around the resonance at $404 \mathrm{keV}$ for $\mathrm{AlHf}_{x} \mathrm{Si}_{y} \mathrm{O}_{z}$ film on $\mathrm{Si}$ : As-deposited sample (squares), and ${ }^{18} \mathrm{O}_{2}$ annealed at $800{ }^{\circ} \mathrm{C}$ for $90 \mathrm{~s}$ (triangles).

Figure 8 shows the excitation curves of the ${ }^{27} \mathrm{Al}(p, \gamma)^{28} \mathrm{Si}$ reaction, corresponding to samples 1 and 6 . The Al distribution is narrower than that of $\mathrm{Si}, \mathrm{O}$, and $\mathrm{Hf}$, which indicates that there is a certain level of segregation of $\mathrm{Al}$ in the nearsurface regions of the films. Slightly wider aluminum distribution is observed after annealing and there is no noticeable aluminum loss.

NNRP also shows a progressive incorporation of oxygen from the gas phase into the solid film, as shown in Fig. 9. For the lowest annealing temperatures $\left(600^{\circ} \mathrm{C}\right.$ and $\left.800^{\circ} \mathrm{C}\right)$, the propagating ${ }^{18} \mathrm{O}$ front barely reaches only the $\mathrm{AlHf}_{x} \mathrm{Si}_{y} \mathrm{O}_{z} / \mathrm{Si}$ interface, whereas at $1000{ }^{\circ} \mathrm{C}$ a substantial amount of ${ }^{18} \mathrm{O}$ is supplied to the interface.

$\mathrm{AlHf}_{x} \mathrm{Si}_{y} \mathrm{O}_{z}$ ultrathin films revealed to be very stable on silicon upon annealing in $\mathrm{O}_{2}$ without dramatic changes in the

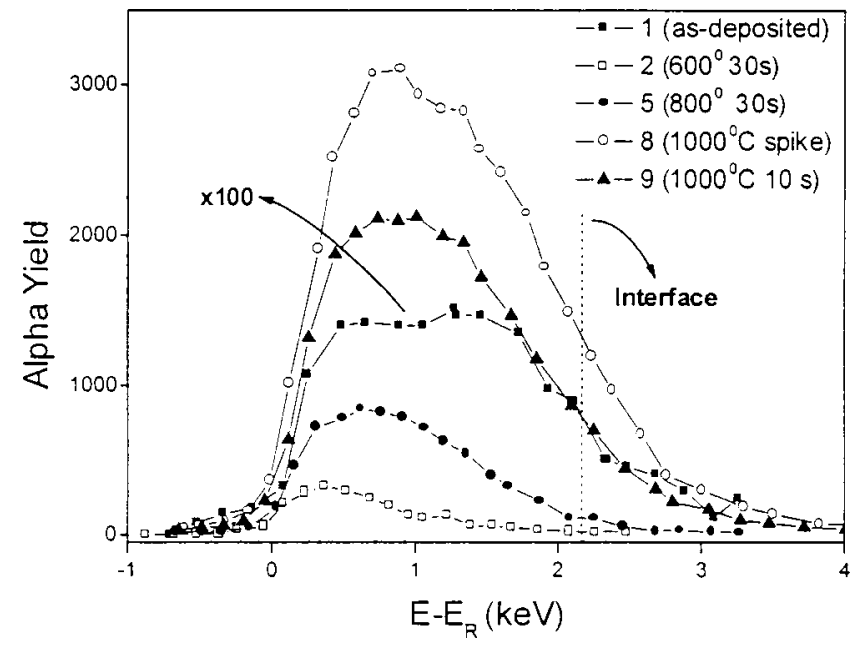

FIG. 9. Excitation curves of the ${ }^{18} \mathrm{O}(p, \alpha){ }^{15} \mathrm{~N}$ nuclear reaction around the resonance at $151 \mathrm{keV} \mathrm{AlHf}_{x} \mathrm{Si}_{y} \mathrm{O}_{z}$ film on $\mathrm{Si}$ : As-prepared sample (solid squares, $\times 10$ ), annealed at $600{ }^{\circ} \mathrm{C}$ for $30 \mathrm{~s}$ (open squares), at $800{ }^{\circ} \mathrm{C}$ for 30 $\mathrm{s}$ (solid circles), at $1000{ }^{\circ} \mathrm{C}$ for $1 \mathrm{~s}$ (spike annealing-open circles), and annealed at $1000{ }^{\circ} \mathrm{C}$ for $10 \mathrm{~s}$ (solid triangles). The annealings were performed in $7 \times 10^{3} \mathrm{~Pa}$ of $\mathrm{O}_{2}$ enriched to $97 \%$ in the ${ }^{18} \mathrm{O}$ isotope $\left({ }^{18} \mathrm{O}_{2}\right)$. The vertical line marks the interface position in the as-deposited sample. composition of the films. It should be stressed here that the total amounts of oxygen from the gas phase incorporated in these films are much smaller than the corresponding ones incorporated in the hafnium oxide or hafnium-silicate films.

\section{CONCLUSIONS}

In summary, we have investigated the integrity and stability of $\mathrm{HfO}_{2}$-based ultrathin films deposited on $\mathrm{Si}$, when they are submitted to typical postdeposition thermal processing used on CMOS fabrication technology.

In the case of $\mathrm{HfO}_{2}$ films on $\mathrm{Si}$, the present characterizations indicate an intermediate layer of complex composition between the room-temperature chemical vapor deposition $\mathrm{HfO}_{2}$ films and the Si substrate, including silicon oxynitride, hafnium-silicate, and possibly hafnium-silicon oxynitride. The composition of this structure is essentially stable against Ar preannealing at $1000{ }^{\circ} \mathrm{C}$ and $\mathrm{O}_{2}$ annealing at $800^{\circ} \mathrm{C}$. Oxygen migration proceeds by means of a propagating front from the surface that reacts with the $\mathrm{HfO}_{2} / \mathrm{SiO}_{x} \mathrm{~N}_{y}$ network as it advances, the main reaction channels being $\mathrm{O}-\mathrm{O}$ and $\mathrm{O}-\mathrm{N}$ exchanges.

Concerning hafnium-silicate, if one considers that RTA at $1000^{\circ} \mathrm{C}$ for $30 \mathrm{~s}$ is sufficient for most dopant-annealing processing steps, the present results assure good integrity of amorphous films deposited by reactive sputtering on $\mathrm{Si}$ with a $\mathrm{SiO}_{2}$ interlayer. Preannealing in a nonreactive atmosphere like $\mathrm{N}_{2}$ increases the stability and resistance to oxidation of the films. Annealing in a oxygen-containing atmosphere reveals a very fastly propagating front of oxygen from the film surface, which reacts with the $\left(\mathrm{HfO}_{2}\right)_{1-x}\left(\mathrm{SiO}_{2}\right)_{x}$ network as it advances. Oxygen exchange is the main reaction channel, although oxygen incorporation to complete the pseudobinary alloy stoichiometry and to oxidize a Si substrate are alternative active reaction channels. The addition of $\mathrm{Al}$ to hafniumsilicate, leading to $\mathrm{Al}-\mathrm{Hf}$ silicates, produces dielectric films on $\mathrm{Si}$ that are more resistant to oxygen diffusion and incorporation.

\section{ACKNOWLEDGMENTS}

This work was partially supported by CNPq, PADCT, and FAPERGS.

${ }^{1}$ International Technology Roadmap for Semiconductors, Semiconductor Industry Association, San Jose, California, http://public.itrs.net (2002).

${ }^{2}$ G. D. Wilk, R. M. Wallace, and J. M. Anthony, J. Appl. Phys. 87, 484 (2000).

${ }^{3}$ B. H. Lee, L. Kang, R. Nieh, W. J. Qi, and J. C. Lee, Appl. Phys. Lett. 76, 1927 (2000).

${ }^{4}$ A. I. Kingon, J. P. Maria, and S. K. Streiffer, Nature (London) 406, 1032 (2000).

${ }^{5}$ C. Chaneliere, J. L. Autran, R. A. B. Devine, and B. Balland, Mater. Sci. Eng., R. 22, 269 (1998).

${ }^{6}$ I. J. R. Baumvol, Surf. Sci. Rep. 36, 1 (1999), and references therein ${ }^{7}$ B. W. Busch, W. H. Schulte, E. Garfunkel, T. Gustafsson, W. Qi, R. Nieh, and J. Lee, Phys. Rev. B 62, 13290 (2000).

${ }^{8}$ D. Landheer, X. Wu, J. Morais, I. J. R. Baumvol, R. P. Pezzi, L. Miotti, W. N. Lennard, and J. K. Kim, Appl. Phys. Lett. 79, 2618 (2001).

${ }^{9}$ C. Krug, E. B. O. da Rosa, R. M. C. de Almeida, J. Morais, I. J. R. Baumvol, T. D. M. Salgado, and F. C. Stedile, Phys. Rev. Lett. 86, 4714 (2001).

${ }^{10}$ M. Kundu, N. Miyata, and M. Ichikawa, Phys. Rev. Lett. 78, 1517 (2001). 
${ }^{11}$ J. Morais, E. B. O. da Rosa, L. Miotti, R. P. Pezzi, I. J. R. Baumvol, A. L. P. Rotondaro, M. J. Bevan, and L. Colombo, Appl. Phys. Lett. 78, 2446 (2001).

${ }^{12}$ M. R. Visokay, J. J. Chambers, A. Rotondaro, A. Shanware, and L. Colombo, Appl. Phys. Lett. 80, 3183 (2002).

${ }^{13}$ S. Sayan, S. Aravamudhan, B. W. Busch, W. H. Schulte, F. Cosandey, G. D. Wilk, T. Gustafsson, and E. Garfunkel, J. Vac. Sci. Technol. A 20, 507 (2002).
${ }^{14}$ K. J. Choi, W. C. Shin, and S. G. Yoon, J. Electrochem. Soc. 149, F18 (2002).

${ }^{15}$ G. D. Wilk, R. M. Wallace, and J. M. Anthony, J. Appl. Phys. 89, 5243 (2001).

${ }^{16}$ J. Morais, L. Miotti, G. V. Soares, R. P. Pezzi, S. R. Teixeira, K. P. Bastos, I. J. R. Baumvol, A. L. P. Rotondaro, M. Visokay, and L. Colombo, Appl. Phys. Lett. 81, 1669 (2002). 